\title{
Perawatan Full Overdenture Rahang Atas dan Rahang Bawah dengan Retensi Coping Logam
}

\section{Maxillary and Mandibular Treatment with Metal Coping Retention}

\author{
Bimo Rintoko \\ Bagian Prostodonsia Prodi Kedokteran Gigi Univ. YARSI Jakarta \\ E-mail: bimo.rintoko@yarsi.ac.id
}

KEYWORDS Full overdenture, metal coping

\begin{abstract}
This case will study discussed full overdenture treatment in patient with partial edentulous upper jaw and lower jaw. Understand the treatment of full overdenture by using metal coping retention. 53 years old woman as a housewife comes with a chief complain of missing teeth and a lot of damage teeth that cannot be used to eat. Preliminary treatment and endodontic treatment on 13, 11, 21, 35, 33, 31, 41, 43. Next decuspation all remaining teeth on $13,11,21,22,35,33,31,41,43$. On 13, 11, 21, 35, 33, $31,41,43$ using a single coping with retentive attachment (single attachment). Treatment full overdenture using metal coping retention may be an alternative treatment in partian edentulous maxilla and mandibula.
\end{abstract}

\section{PENDAHULUAN}

Overdenture adalah bagian dari gigi tiruan lepasan baik lengkap maupun sebagian yang bertumpu pada satu atau beberapa gigi asli, akar dari gigi asli dan dental implant, serta dapat disebut juga overlay denture, overlay prosthesis ataupun superimposed prosthesis (The Glossary of Prosthodontic Terms). Istilah inggris biasanya meyebut dengan "overdenture" dan istilah Jerman biasanya disebut "Hybridprothesen", terminologi tersebut mengacu pada gigi tiruan lengkap yang dukungannya bertumpu pada beberapa gigi (Geering. Alfred. H, 1993).

Ide untuk meninggalkan sisa akar gigi pada tulang rahang dengan konstruksi gigi tiruan lengkap di atasnya, sudah terpikirkan sejak 100 tahun yang lalu. Tujuannya adalah memperlambat proses resorbsi dari residual ridge, yang biasanya proses resorbsi ini akan cepat setelah pencabutan gigi. Dengan adanya daya dukung/support dan retensi dari sisa akar,

overdenture ini akan lebih kuat terhadap daya kunyah, kekuatan menggigit, dan tahan terhadap daya tekanan yang lain (Geering. Alfred. H, 1993).

Overdenture mempunyai sejarah yang panjang di dalam perkembangannya. Di Eropa, perkembangan overdenture dipengaruhi oleh alat/unit/devices precision attachment. Berhasil atau tidaknya perawatan overdenture tergantung dari kondisi jaringan periodonsium. Hasil penelitian klinis selama 70 tahun menunjukkan keberhasilan dalam jangka waktu lama. Satu hal yang harus diperhatikan di dalam perawatan overdenture adalah bentuk basis gigi tiruan dan bahan yang menutup sisa akar gigi harus dapat diterima oleh jaringan periodonsium (Geering. Alfred. H, 1993).

Di dalam kasus ini akan akan dijelaskan jenis perawatan overdenture pada pasien dengan kehilangan gigi 
sebagian rahang atas dan rahang bawah dengan desain yang sesuai terhadap sisa gigi penyangga agar dapat berfungsi dengan baik. Tujuan utama dari kasus ini adalah memahami tatalaksana perawatan full overdenture dengan retensi coping logam.

Overdenture adalah bagian dari gigi tiruan lepasan baik lengkap maupun sebagian yang bertumpu pada satu atau beberapa gigi asli, akar dari gigi asli dan dental implant, serta dapat disebut juga overlay denture, overlay prosthesis ataupun superimposed prosthesis (The Glossary of Prosthodontic Terms).

Overdenture dengan dukungan kombinasi antara periodontal dan mukosa mempunyai sejumlah keuntungan yang berarti bila dibandingkan dengan gigi tiruan lengkap. Yang paling penting adalah fungsi stabilitas yang lebih besar untuk menjaga bentuk ridge yang dekat dengan gigi penyangga (dengan atau tidak menggunakan kaitan), retensi yang lebih baik, khususnya bila kaitan digunakan pada protesis di rahang bawah, peningkatan efisiensi pengunyahan karena stabilitas dan retensi yang lebih baik, tekanan pada mukosa berkurang (Geering. Alfred. H, 1993).

Pada bagian palatum perlu ditutup sebagian dan tidak perlu meluaskan basis yang menempel pada palatum bila menggunakan elemen retentif. Hal ini sering memberikan efek psikologis yang baik bagi pasien, kelebihannya yaitu mudah beradaptasi dan merupakan latihan bagi penggunaan gigi tiruan lengkap di kemudian hari dengan menyiapkan lintasan pola refleks yang tepat. Kekurangannya adalah biaya yang lebih besar, hal ini berhubungan langsung dengan luasnya perawatan sebelum pembuatan protesa, dengan menggunakan kaitan retentif dan perawatan pasca insersi. Dibutuhkan kerjasama antara pasien dan dokter giginya untuk merawat protesa (Geering. Alfred. H, 1993).
Terdapat sejumlah faktor non klinis yang perlu diperhatikan dalam seleksi untuk overdenture. Di antaranya adalah sikap pasien terhadap kesehatan giginya, penggunaan gigi tiruan lepasan, kemampuan dan keinginan untuk bekerja sama serta situasi keuangannya (Geering. Alfred. H, 1993).

Indikasi perawatan overdenture adalah tersisa paling sedikit satu gigi yang masih dapat dipertahankan, kebersihan mulut yang cukup baik untuk menghambat atau mencegah karies yang cepat atau kerusakan jaringan periodontal, jika prognosa untuk pemakaian gigi tiruan lengkap buruk karena adanya resorpsi ridge yang berat, xerostomia, refleks muntah yang berat, kemampuan belajar yang kurang, faktor psikologis dan lainlain, kerusakan gigi tersisa tidak sesuai oleh tipe perawatan yang lain, tidak ada tipe perawatan prostetik yang menjanjikan hasil perawatan yang lebih baik, sebanding dengan biaya yang dikeluarkan (Geering. Alfred. H, 1993).

Kontra indikasi perawatan overdenture adalah teknik yang lebih sulit daripada pembuatan gigi tiruan lengkap biasa, kadang-kadang membutuhkan suatu protesis sementara sebelum pembuatan protesis definitive seperti provisional denture, kebutuhan protesis transisional harus memperhatikan prognosis oral hygiene pasien dan keadaan sisa gigi penyangga sebagai abutment (George A. Zarb, 1990), perawatan overdenture membutuhkan teknik yang lebih kompleks seperti diperlukannya perawatan endodontik dan pada kondisi tertentu memerlukan coping logam, sehingga membutuhkan biaya yang lebih mahal (Barclay. C.W., 2001).

Ada bermacam-macam pilihan yang tersedia bagi dokter gigi untuk dukungan dan retensi overdenture. Disamping disaindisain yang lebih kompleks dan mahal ada juga cara-cara yang sederhana dengan biaya yang tidak terlalu membebani pasien. Hal ini juga berlaku untuk kasus- 
kasus dengan prognosis yang kurang menguntungkan. Semua unsur pendukung untuk overdenture seluruhnya tertutup oleh protesa lepasan oleh karena itu tidak terlihat. Jenis dan kompleksnya disain dan jenis perawatan yang dibutuhkan oleh gigi penyanggga sangat dipengaruhi oleh biaya (Geering. Alfred. H, 1993).

\section{METODOLOGI}

Penderita dengan jenis kelamin wanita umur 53 tahun dengan pekerjaan sebagai ibu rumah tangga (Gambar 1). Datang dengan keluhan utama gigi sudah banyak yang rusak sehingga tidak dapat digunakan untuk makan. Penderita datang ingin dibuatkan gigi tiruan. Beberapa gigi telah dicabut beberapa tahun yang lalu karena keropos. Penderita tidak pernah memakai gigi tiruan. Pemeriksaan klinis ekstra oral penderita pada temporo mandibular joint, mata, hidung tidak ada kelainan dan bentuk wajah tappered. Keadaan Intra oral penderita diketahui ada gigi hilang, gigi karies, gigi atrisi, gigi rotasi dan karang gigi. Keadaan jaringan lunak terdapat resesi gingiva (Gambar 2). Kajian radiografi panoramik geligi penderita (Gambar 3) yaitu jaringan penyangga/ tulang alveolar crest pada regio anterior terdapat gambaran resorbsi horizontal, pada bagian apikal sisa akar 37 terdapat radiolusent.
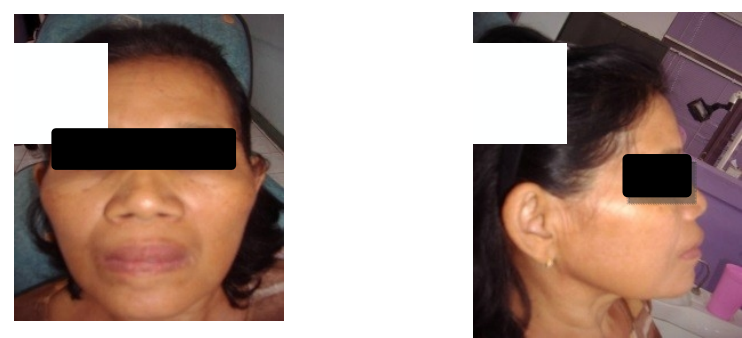

Gambar 1. Profil penderita (A) tampak depan, (B) tampak samping.
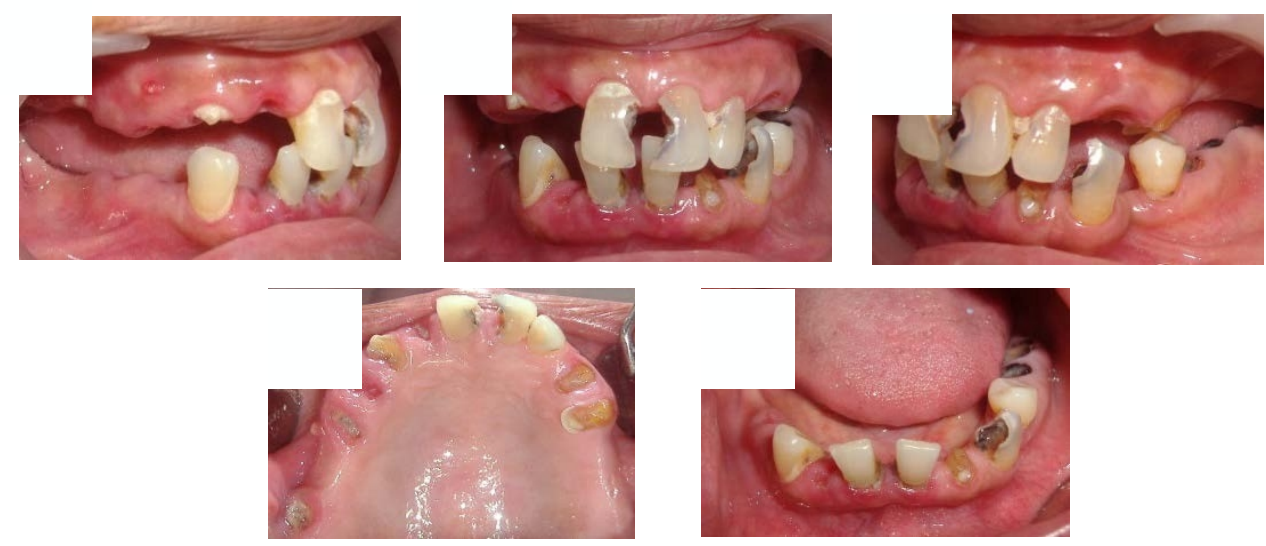

Gambar 2. Intra oral penderita (A) Tampak samping kanan, (B) Tampak depan, (C) Tampak samping kiri, (D) Rahang atas, (E) Rahang bawah. 


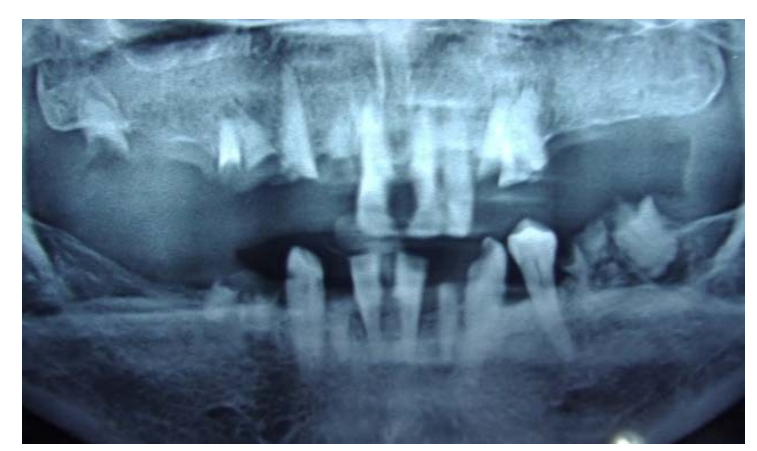

Gambar 3. Foto panoramik penderita.

Diagnosis untuk kasus ini adalah gigi hilang pada $18,16,25,26,27,28,38$, $3446,47,48$, gangraen radiks pada $17^{\checkmark}$, $15^{\sqrt{ }}, 14^{\sqrt{ }}, 13^{\sqrt{ }}, 12^{\sqrt{ }}, 23^{\downarrow}, 24^{\sqrt{ }}, 37^{\downarrow}, 36^{\sqrt{ }}, 32^{\downarrow}$, $42^{\sqrt{ }}, \quad 44^{\sqrt{ }}, \quad 45^{\sqrt{ }}$, periodontitis kronis marginalis pada $11,12,21,35,33,31,41$, 43. Di dalam kasus ini dibutuhkan perawatan pendahuluan sebelum dilakukan perawatan definitif, yaitu pro perawatan endodontik pada $13,11,21,22,35,33,31$, 41,43 , pro skaling pada seluruh gigi yang tersisa, pro ekstraksi $17^{\sqrt{ }}, 15^{\sqrt{ }}, 14^{\sqrt{ }}, 12^{\sqrt{ }}$, $23^{\vee}, 24^{\vee}, 37^{\vee}, 36^{\vee}, 32^{\vee}, 42^{\downarrow}, 44^{\downarrow}, 45^{\downarrow}$.
Desain Gigi Tiruan pada kasus ini adalah Full Overdenture rahang atas dengan retensi coping logam pada 13, 11, 21, 22, menggunakan anasir gigi akrilik pada $17,16,15,14,13,12,11,21,22,23$, $24,25,26,27$, basis gigi tiruan menggunakan basis akrilik (Gambar 4) sedangkan desain rahang bawah adalah Full Overdenture dengan retensi coping logam pada $35,33,31,41,43$, anasir gigi pada $37,36,35,34,33,32,31,41,42,43$, $44,45,46,47$, basis gigi tiruan menggunakan basis akrilik.

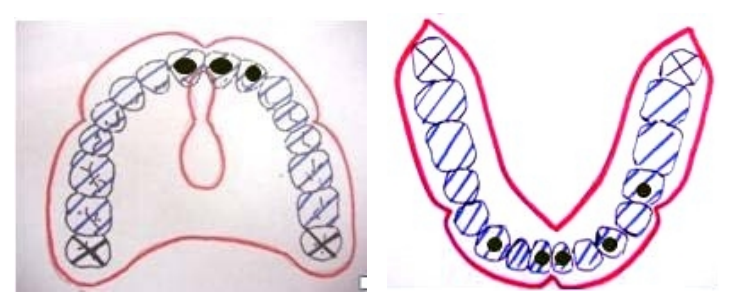

Gambar 4. Disain Rahang Bawah
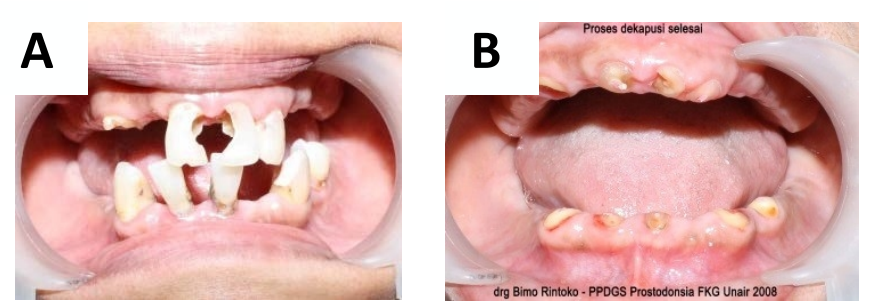

Gambar 5. (A) Sebelum dekaputasi, (B) Sesudah dekaputasi

\section{KASUS}

Tahapan Perawatan kasus ini yaitu : Perawatan pendahuluan dan persiapan gigi dengan dilakukan terlebih dahulu perawatan endodontik pada $13^{\vee}, 11,21$,
35, 33, 31, 41, 43. Selanjutnya adalah dekaputasi pada semua gigi yang tersisa yaitu $13,11,21,22,35,33,31,41,43$. 
Proses selanjutnya adalah preparasi saluran akar, sebelum dilakukan pencetakan, terlebih dahulu dilakukan preparasi saluran akar kira-kira 2/3 akar. Preparasi ini untuk core atau seat bagi coping. Pada 13, 11, 21, 35, 33, 31, 41, 43 menggunakan coping dengan perlekatan retentif tunggal (single attachment), guttap pada saluran akarnya dikeluarkan dengan gates glidden dril. Saluran akarnya dilebarkan kurang lebih 1/3 lebar akar dengan menggunakan jarum reamer ( sampai no. 120) dan panjang preparasi 6 $\mathrm{mm}$. Kemudian dibuatkan seat berbentuk bulat sebagai tempat kedudukan keeper dengan kedalaman $2 \mathrm{~mm}$ dari oklusal dan lebar sedikit lebih besar dari $4 \mathrm{~mm}$ menggunakan flat end tapered bur. Pada daerah marginal dibuat bevel dengan preparasi berbentuk chamfer.

Dilanjutkan dengan pencetakan saluran akar untuk model kerja cast coping. Pada tahap ini (1) Siapkan tusuk gigi kayu dengan diameter $0,6 \mathrm{~mm}$ yang telah di potong sepanjang $10 \mathrm{~mm}$, salah satu bagian guratan-guratan untuk retensi bahan cetak. Tujuan pemakaian tusuk gigi kayu ini adalah untuk mencetak saluran akarnya. (2) Disiapkan bahan elastomer (polyvinylsiloxane) : light body (Flexitime ${ }^{\circledR}$ correct flow) dan putty (Flexitime ${ }^{\circledR}$ easy putty). Setelah siap, base dan catalist putty dicampur dan ditempatkan dalam stock tray. (3) Saat yang bersamaan light body juga dicampurkan dan dimasukkan dalam saluran akar dengan jarum lentulo dan diputar tujuannya agar bahan cetak merata pada saluran akar kemudian tusuk gigi kayu dimasukkan kedalam saluran akar. (4) Light body juga diletakkan diatas putty pada stock tray regio gigi penyangga yang dibuat cast keeper dan cast coping, kemudian dicetakkan pada mulut penderita. (5) Setelah setting cetakan dikeluarkan dari dalam mulut.(6) Saluran akar 13, 11, 21, 35, 33, 31, 41, 43 ditutup dengan semen sementara. (7) Pengiriman ke dental lababoratorium untuk pembuatan coping logam / cast coping. Setelah proses coping di laboratorium selesai dilakukan insersi cast coping, yaitu pasang coba cast coping (Gambar 6). Coping logam harus menutup gigi-gigi penyangga dengan rapat pada bagian servikal. Insersi cast coping dengan luting glass iononomer cement Tahap selanjutnya adalah pembuatan individual tray rahang atas dan rahang bawah, border moulding rahang atas dan rahang bawah. Pencetakan fungsional rahang atas dan rahang bawah dengan bahan elastomer medium bodied consistency (polyvinylsiloxane, Provil® Novo ) dengan menggunakan teknik monophase impresion technique. Sebelum dilakukan pencetakan, malam yang menempel di individual tray dibuang terlebih dahulu. Tahap selanjutnya adalah pembuatan individual tray rahang atas dan rahang bawah, border moulding rahang atas dan rahang bawah. Pencetakan fungsional rahang atas dan rahang bawah dengan bahan elastomer medium bodied consistency (polyvinylsiloxane, Provil ${ }^{\circledR}$ Novo ) dengan menggunakan teknik monophase impresion technique. Sebelum dilakukan pencetakan, malam yang menempel di individual tray dibuang terlebih dahulu.

Tahap selanjutnya adalah pembuatan individual tray rahang atas dan rahang bawah, border moulding rahang atas dan rahang bawah. Pencetakan fungsional rahang atas dan rahang bawah dengan bahan elastomer medium bodied consistency (polyvinylsiloxane, Provil ${ }^{\circledR}$ Novo ) dengan menggunakan teknik monophase impresion technique. Sebelum dilakukan pencetakan, malam yang menempel di individual tray dibuang terlebih dahulu.

Pembuatan model kerja rahang atas dan rahang bawah. Setelah pembuatan model kerja di laboratorium tahap selanjutnya adalah penetapan gigit. Dilakukan penetapan gigit dan pengukuran 
vertical dimension occlusion (VDO). Pemasangan model kerja dan galengan gigit dalam artikulator. Dilanjutkan dengan penyusunan anasir gigi rahang atas dan rahang bawah di dalam artikulator. Selanjutnya adalah pasang coba gigi tiruan malam di dalam mulut penderita. Setelah tahap konturing akhir, prosesing (packing) akrilik gigi tiruan rahang atas dan rahang bawah, Remounting I dan selective grinding I, Remount jig, pulas awal, interocclusal record, remounting II dan selective grinding II serta pulas akhir, pada penderita dilakukan insersi gigi tiruan. Instruksi kepada penderita setelah insersi : gigi tiruan dipakai selama 24 jam pertama setelah insersi dan pada malam hari tidak dilepas sampai keesokan harinya, gigi tiruan boleh dipakai untuk minum dan berbicara, tetapi tidak boleh untuk makan, kontrol pada keesokan harinya.

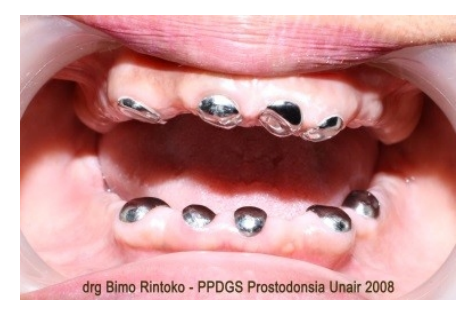

Gambar 6. Cast coping telah diinsersikan
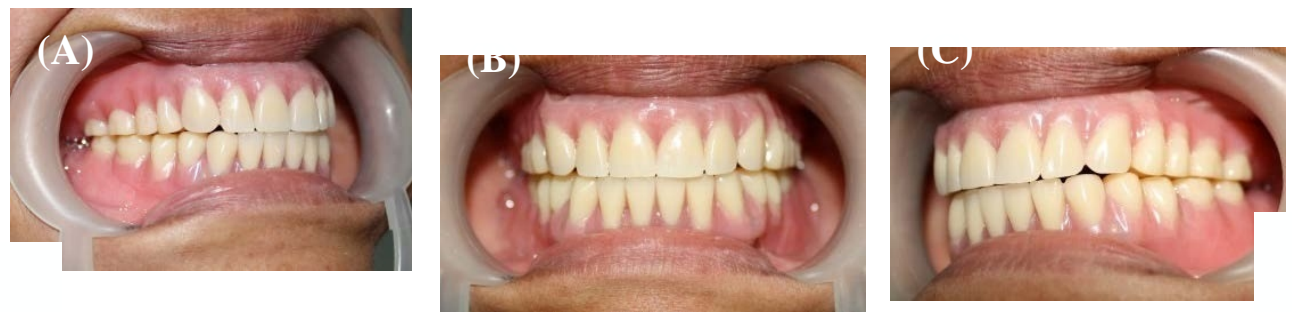

Gamua ,. (A) dan (B) Insersi gigi tiruan tampak samping kiri dan kanan, (C) Insersi gigi tiruan tampak depan

ISI

Di dalam kasus ini gigi yang tersisa hampir semuanya telah mengalami karies yang meluas, oleh karena itu desain perawatan ini adalah full overdenture dengan perlekatan tunggal (single attachment) yaitu cast coping. Di dalam kasus ini cast coping dipasang pasa semua gigi yang tersisa, yaitu 13, 11, 21, 22, 35, 33, 31, 41, 43 (Gambar 6).

Sebelum dilakukan dekaputasi pada $13,11,21,22,35,33,31,41,43$ harus dilakukan perawatan saluran akar terlebih dahulu pada gigi tersebut (Gambar 5). Kasus kehilangan banyak gigi dalam jangka waktu lama, seringkali sisa gigi yang ada mengalami masalah periodontal seperti adanya kegoyangan gigi yang parah disertai dengan perubahan posisi seperti: protrusi, ekstrusi, rotasi maupun diastema ganda (Iskandar, 1995). Oleh karena itu pada kasus ini dipilih desain Full Overdenture dengan retensi coping logam. Di dalam kasus ini menggunakan cast coping agar meminimalkan terjadinya karies pada gigi penyangga overdenture. Dalam hal ini diagnosis, prognosis dan rencana perawatan pada penderita dengan kelainan periodontal, sangatlah penting karena berperan pada keberhasilan perawatan periodontik (Carranza \& 
Newman, 2006) dan menunjang keberhasilan jangka panjang, kenyamanan dan fungsional dari perawatan prostodontik (Jumber, 1981). Di dalam membuat perencanaan overdenture ada empat parameter dimana kondisi klinis yang nyata dari setiap gigi dan prognosisnya harus saling berhubungan. Parameter itu adalah (1) lokasi strategis dari tiap gigi, (2) beban yang akan ditahan, (3) kebersihan mulut penderita serta (4) perluasan perawatan yang diperlukan untuk mempertahankan gigi (Geering., 1993). Keuntungan yang paling penting di dalam perawatan overdenture dengan kehilangan sebagian gigi rahang atas dan rahang bawah adalah (1) Fungsi stabilitas yang lebih besar untuk menjaga bentuk ridge yang dekat dengan gigi penyangga (dengan atau tidak menggunakan kaitan). (2) Retensi yang lebih baik, khususnya bila kaitan digunakan pada protesis di rahang bawah. (3) Peningkatan efisiensi pengunyahan karena stabilitas dan retensi yang lebih baik. (4) Tekanan pada mukosa berkurang (Geering. Alfred. H, 1993).

Spektrum indikasi untuk over denture meliputi perawatan jangka pendek dalam persiapan untuk gigi tiruan lengkap sampai perawatan definitif jangka panjang. Klasifikasi dapat dibuat berdasarkan berapa lama protesa diperkirakan akan digunakan, yaitu (1) Overdenture immediate, (2) Overdenture transitional, (3) Overdenture definitif. Jenis overdenture yang dibuat di atas ditentukan oleh seberapa jauh prognosis bagi gigi yang tersisa (Geering. Alfred. H, 1993). Di dalam kasus ini perawatan overdenture yaitu untuk perawatan jangka panjang dan merupakan overdenture definitif dengan menggunakan single attachment/single coping, untuk meminimalkan terjadinya karies pada gigi penyangga.

Perawatan gigi tiruan dengan teknik overdenture dapat menambah kestabilan gigi tiruan dan mempertahankan tinggi tulang alveolar. Faktor penting dalam pemilihan gigi penyangga adalah keadaan periodontium dan tulang alveolar di sekeliling gigi. Akar yang dipertahankan dapat diterima oleh jaringan dan membentuk suatu ligamen periodontal ( Zarb, 1997).

Kontrol I dilakukan 24 jam setelah insersi. Penderita merasa sangat puas dengan estetik gigi-giginya. Kemudian penderita diinstruksikan makan dan minum yang lunak, pada malam hari gigi tiruan dilepas, dibersihkan dengan sikat gigi berbulu lembut menggunakan sabun mandi, jangan menggunakan pasta gigi karena bersifat abrasif kemudian direndam air bersih dalam gelas. Penderita diminta kontrol kembali 3 hari lagi.

Kontrol ke II dilakukan 4 hari setelah insersi. Retensi, stabilitas dan oklusi gigi tiruan tetap baik. Penderita diinstruksikan mulai dapat makan seperti biasa tetapi tidak makan makanan yang keras dan lengket, pada malam hari gigi tiruan dilepas dan dibersihkan kemudian direndam dengan air dalam gelas.

Kontrol III dilakukan setelah 1 minggu kontrol II, tidak ada keluhan rasa sakit yang disampaikan oleh penderita. Gigi tiruannya sudah digunakan untuk makan seperti biasa dan penderita juga sudah dapat berbicara dengan baik dan jelas. Pemeriksaan retensi, stabilitas dan oklusi baik. Pemeriksaan pada gigi-gigi penyangga tidak ditemukan adanya kemerahan, keradangan maupun bertambahnya kegoyangan gigi. Penderita mengharapkan pembuatan gigi tiruan yang akan datang bagian palatum dibuat terbuka agar lebih merasa nyaman.

Setelah kontrol ke IV penderita baru merasa nyaman dengan gigi tiruannya. Tidak temukan adanya kemerahan dan keradangan pada mukosa. Penderita diinstruksikan untuk kontrol secara periodik minimal 3 bulan sekali. 


\section{PENUTUP}

Hilangnya banyak gigi pada rahang atas dan rahang bawah menyebabkan penderita tidak dapat makan dengan baik, oleh karena itu dibutuhkan suatu perawatan gigi tiruan yang meminimalkan terjadinya resorbsi pada tulang alveolar. Perawatan gigi tiruan dengan desain full overdenture dengan retensi coping logam dapat dijadikan alternatif perawatan pada penderita dengan kehilangan gigi yang banyak pada rahang atas dan rahang bawah.

\section{DAFTAR PUSTAKA}

Ai M, Shiau YY. 2004. New magnetic application in clinical dentistry. Quintessence Publ Co Ltd, Tokyo: p. 28-69.

Carranza, F.A. and Newman, M. G. 2006. Clinical periodontology, $10^{\text {th }}$., W. B. Saunders Comp., Phil-LondonToronto: p. 100-107, 120-128, 157164, 467-477, 494-499, 500-504.

Geering. Alfred. H. 1993. Complete Denture And Overdenture Prosthetics. Georg Thieme Verlag, Stuttgard, New York.

Heartwell CM and Rahn AO. 1986. Syllabus of complete dentures, $4^{\text {th }} \mathrm{ed}$,
Lea \& Febiger, Philadelphia: p.487497.

Iskandar R. 1995. Perawatan prostodonsi preventif dengan overdenture pada berbagai rahang. Buku Kumpulan Makalah Ilmiah Kongres XIX PDGI, Balikpapan; p: 81-85.

Jumber JF. 1981. An atlas of overdenture and attachment. Quintessence Publishing Co Inc, Chicago; p. 17, 20-23, 113-152.

The Journal of Prosthetic Dentistry., July 2005. The Glossary of Prosthodontic Terms. The Academy of Prosthodontics, Vol. 94 number 1.; p. 51, 65.

The Academy of Prosthodontics. July 2005. The Glossary of Prosthodontic Terms. Journal of Prosthetic Dentistry. Volume-94. no.1.

Tan HK. 1997. A preparation guide for modifiying the mandibular teeth before making a maxillary single complete denture. J Prosthet dent; 77: 321-322

Zarb GA. 1997. Boucher's Prosthodontics Treatment for Edentulous Patients. $11^{\text {th }}$ ed, St.Louis : The C.V Mosby Company. $\mathrm{p}:$ : 521-

63. 
